\title{
A Parametric Experimental Investigation of the Operating Conditions of Gravitational Vortex Hydropower (GVHP)
}

\author{
Christine Power, Aonghus McNabola, and Paul Coughlan
}

\begin{abstract}
Global energy consumption is growing considerably, raising such issues as increased energy-related greenhouse gas emissions, reduced security of supply, and growing fuel costs. Renewable resources, such as hydropower, offer an alternative energy source to meet the growing demand. Small hydropower (SHP) has been a major focus of hydropower research in recent years, as many of the large scale hydroelectric opportunities around the world have already been exploited. In particular, low head SHP is gaining interest as traditional turbines, such as the Kaplan and Pelton turbines, are typically limited to heads greater than $3 \mathrm{~m}$. Gravitational vortex hydropower (GVHP) is one such low head hydropower solution. GVHP exploits the energy available in a vortex flow, enabling hydropower generation at heads as low as $0.7 \mathrm{~m}$. A vertical axis turbine is placed in the centre of a vortex flow and rotates with the flow, thus generating mechanical energy.

This paper describes a parametric experimental investigation of the operating conditions of GVHP. Various flow rates, inlet conditions, blade sizes and blade numbers were tested and the turbine rotational speed, vortex height and applied resistance force were recorded for each setting. The power input, power output and efficiency were then calculated and compared for the various settings. It was found that the turbine efficiency increases with blade size and blade number for the blade configurations tested. Maximum power outputs were found for the largest flow rate tested and when there was a considerable resistance force applied to the turbine. Finally, of three inlet heights tested, a height of $25 \mathrm{~cm}$ above the tank base (35\% of the overall tank height) was found to be optimum for turbine performance. These results have implications both for future research and for practice, with energy generating applications in low head rivers and in wastewater networks.
\end{abstract}

Index Terms-Clean energy, experimental model, gravitational vortex hydropower (GVHP), low head, new energy device.

\section{INTRODUCTION}

Energy consumption around the world is increasing; the global primary energy supply has more than doubled between 1973 and 2012. Furthermore, there is a strong dependence on fossil fuel based energy. In 2012, 81.7\% of the total primary energy supply came from fossil fuels and only $13.5 \%$ was from renewable sources [1]. This raises security of supply issues as fossil fuels, the primary source in the current and predicted future fuel mixes, are in finite supply. Increasing

Manuscript received January 5, 2015; revised May 12, 2015. This research was part funded by the European Regional Development Fund through the INTERREG Ireland-Wales Programme (Interreg 4A).

C. Power and A. McNabola are with the Department of Civil, Structural and Environmental Engineering, Trinity College Dublin, Ireland (e-mail: powerch@tcd.ie, amcnabol@tcd.ie).

P. Coughlan is with the School of Business, Trinity College Dublin, Ireland (e-mail: coughlnp@tcd.ie). demand coupled with a limited supply has caused fossil fuel prices to soar in recent years [2], [3]. There are also significant environmental implications associated with our growing consumption of fossil-fuel based energy. Global $\mathrm{CO}_{2}$ emissions from energy fuels more than doubled between 1973 and 2012 [1].

Renewable resources, such as hydro, offer an alternative source of energy to meet the growing demand. Renewable energy sources increase the sustainability and security of supply of the energy sector. Hydropower is an age-old and proven form of energy conversion, with the earliest evidence dating back to B.C., when the energy available in water was harnessed using water wheels [4], [5]. There have been numerous improvements and applications since then and in 2012 hydropower contributed $16.2 \%$ to the total global electricity generation [1]. The environmental impact of hydropower generation is low, with zero greenhouse gas emissions during the operation of hydropower plants. Small hydropower (SHP), less than 10MW according to European standards, is particularly beneficial as dams are not required, thus further reducing the environmental impact [6]. Also, whereas large scale hydropower generation is limited by a scarcity of sites with adequate potential, it is estimated that only $5 \%$ of the global SHP potential has been exploited to date and that the total potential capacity could be as high as 150-200 GW [7], [8].

Traditional turbines, such as the Kaplan and Pelton turbines, can be scaled down for SHP applications but are typically limited to heads greater than $3 \mathrm{~m}$. However, many sites with such heads available, particularly in Europe and other developed regions, have already been exploited and so the greatest scope for SHP often lies in low head sites which tend to be more difficult and costly to exploit using established turbine technology [9]. At low head sites, relatively large flow rates are needed to generate useful power outputs and so the physical size of the electromechanical equipment is larger than that required for high-head low-flow conditions [10], [11]. Various new low head hydropower techniques and devices are therefore being developed, such as gravitational vortex hydropower (GVHP) and hydrokinetic turbines [12], [13].

GVHP exploits the energy available in a vortex flow. A vortex is generated, typically in a circular basin with a tangential inlet and a central outlet, as shown in Fig. 1. A vertical axis turbine is placed in the centre of the vortex, where the rotational speed is the highest. The turbine rotates with the swirling flow, thus generating mechanical energy which can be converted to electrical energy using a generator. As detailed in Section II, there have been few research studies or commercial projects on this concept to date. The research 
study reported on in this paper was developed in response to this gap in knowledge. A laboratory scale model of a GVHP plant was developed and experimental tests were carried out at a variety of tank and turbine settings to investigate and to optimize the operating conditions for hydropower generation.

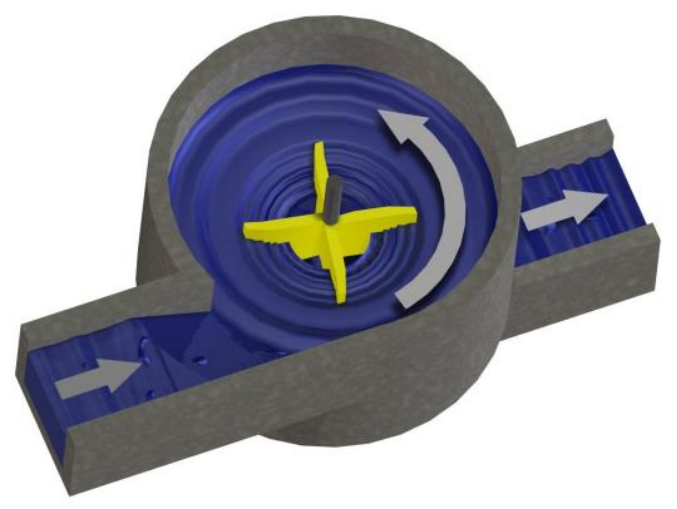

Fig. 1. Schematic diagram of GVHP [14].

\section{BACKGROUND}

Vortex formation has been a subject of research interest [15]-[17] as vortices can be both useful, such as for cyclone separators [18], [19], and harmful, such as to hydraulic machinery and structures in hydropower plants [20], [21]. However, the application of vortices for hydropower generation, GVHP, has not been considered in detail to date. GVHP research and practice is only a few years old, and thus the operating conditions are largely unknown and/or untested. The concept has been mentioned briefly in general papers about low head SHP [13], [22], [23] but there are very few studies such as this that are solely focused on the analysis of GVHP in detail.

\section{A. Numerical GVHP Studies}

The earliest full paper on GVHP describes a numerical simulation of a vertical axis turbine with blades of decreasing radius at different depths within a conical tank [24]. In the absence of a turbine, the cavern height formed by the vortex was found to be proportional to the rotational speed of the water and the tank radius. When the turbine was introduced in the analysis, it was found that this cavern height is a major influence on the power available to the turbine. While useful flow descriptions were provided by [24], the implications for power generation were not considered.

Wanchat and Suntivarakorn [25] used computational fluid dynamics (CFD) to simulate and compare the vortex formation in three tank configurations; a cylindrical tank with a central outlet at the base, a rectangular tank with pre-rotation using a guide plate and an outlet at the base, and a cylindrical tank with pre-rotation and a central outlet at the base. The effect of a turbine on vortex formation was not considered in the numerical simulation. The most stable and well-formed vortex was found in the cylindrical tank with pre-rotation. The tank was $1 \mathrm{~m}$ in diameter and $1 \mathrm{~m}$ high and the outlet was $0.2 \mathrm{~m}$ in diameter. This is quite a large outlet tank ratio so experimental verification would be required. Also a direct comparison between the cylindrical tank with and without and pre-rotation was missing, so it is inconclusive as to whether or not the inlet guide plate improves the vortex flow field.

\section{B. Numerical \& Experimental GVHP Studies}

While numerical modelling tools such as CFD are useful for understanding the flow patterns within a GVHP plant, experimental models are needed to verify the simulated results. This is especially important for such a new and largely untested concept as GVHP. For this reason, the cylindrical tank with guiding inlet plate described in [25] was constructed for laboratory testing by the same team of researchers [26]. A 5-blade vertical axis turbine connected by belt to a pulley and generator was placed in the centre of the tank. The turbine and generator speeds and the water height in the tank were recorded for seven outlet diameters between $0.1 \mathrm{~m}$ and $0.4 \mathrm{~m}$. The authors concluded that the optimum outlet diameter for a $1 \mathrm{~m}$ diameter cylindrical tank was in the range of $0.2-0.3 \mathrm{~m}$. The resulting vortex height was between $0.3 \mathrm{~m}$ and $0.4 \mathrm{~m}$. The maximum power output was found to be $60 \mathrm{~W}$ at the $0.2 \mathrm{~m}$ diameter outlet (and a water height of $0.4 \mathrm{~m}$ ), resulting in a system efficiency of $30 \%$ [26]. However, the calculations used to obtain the input and output powers were not provided. Based on the flow rate and water height values given, we calculated a lower efficiency range (of 13.6-25.5\%) than that reported by [26].

Kueh et al. [27] also used both numerical and experimental models, but focused solely on the tank configuration for vortex formation and did not consider the effect of a turbine placed within the flow. The tank analyzed was open-topped and cylindrical with a tangential inlet at the top and a central outlet hole at the bottom. The tank was $0.75 \mathrm{~m}$ high and $0.4 \mathrm{~m}$ in diameter. Two outlet diameters, $0.02 \mathrm{~m}$ and $0.025 \mathrm{~m}$, and various inflow rates in the range of $0.37-0.675 \mathrm{~L} / \mathrm{s}$ were tested. The resulting vortex heights, measured as the maximum water height at the tank wall, ranged between $0.15 \mathrm{~m}$ and $0.53 \mathrm{~m}$. The flow within this experimental model was also simulated using CFD and the results of both models were said to match. The tank was assumed to be initially filled to $0.5 \mathrm{~m}$. At both outlet diameters, the tank drains initially until the outflow matches the inflow at which point the steady state water height was measured. In agreement with previous studies on vortices, the vortex strength was seen to increase with increasing vortex height.

\section{Experimental GVHP Studies}

GVHP was investigated experimentally as a solution for the low head water resources available in the Terai region of Nepal [28]. The laboratory model used consisted of a cylindrical tank, $0.85 \mathrm{~m}$ high and $0.6 \mathrm{~m}$ in diameter, with various vertical axis turbines placed in the centre. Turbines with 3, 6 and 12 curved blades were tested. Two blade lengths were compared for the various turbines. The outlet diameter, $0.11 \mathrm{~m}$, was quite large relative to the tank diameter. A large inflow rate of $8.6 \mathrm{~L} / \mathrm{s}$ was therefore needed to ensure vortex formation. A constant head of $0.78 \mathrm{~m}$ was assumed. In reality, however, the water height in the tank varies with turbine type. A Prony brake dynamometer, similar to that used for this study, was used to measure the torque on the turbine. It appears from the torque values given that the effective radius of the dynamometer is $0.49 \mathrm{~m}$. This is quite large, given that 
the tank radius is $0.3 \mathrm{~m}$. As a result, the calculated torque and therefore power output values are high and the turbine efficiency was found to be in the range of $10.5 \%-25.4 \%$.

The optimal turbine location was found to be at the bottom of the tank as the velocity head increases with depth. Also, the maximum powers and efficiencies were found when fewer blades were used. As will be discussed later, the results of this paper show the opposite finding. However, 2 and 4 blades were compared in this study whereas [28] use up to 12 blades. This suggests that while more blades will extract greater power due to increased torque, there is an optimum number beyond which any additional blades will increase the turbine weight too much. Of the two blade lengths tested, $0.08 \mathrm{~m}$ and $0.2 \mathrm{~m}$, the shorter length was found to be more efficient. A conical tank was also tested. Greater powers and efficiencies were found compared to the cylindrical tank. However, only two tests were conducted, both using the same 12-blade turbine. Finally, a numerical test of a site rig on a river in Nepal was discussed. However, the basis of analysis is vortex strength rather than power output so it remains unclear how GVHP would perform in a larger setting [28].

The final experimental paper found by the authors describes a prototype model of an 8-blade vertical axis turbine placed in the centre of a cylindrical tank $(1.2 \mathrm{~m}$ high and $1.5 \mathrm{~m}$ in diameter) with a tangential inlet and a central outlet at the base [29]. The crucial parameters for vortex strength are listed as inflow rate, tank radius and height and outlet diameter. However, the outlet diameter for the prototype is not given. The turbine blades are each $1 \mathrm{~m}$ long and reduce in width with distance from the top. An inflow rate of $0.03 \mathrm{~m}^{3} / \mathrm{s}$ and a vortex rotational speed of $60 \mathrm{RPM}$ were recorded. The theoretical maximum power was calculated to be $2.7 \mathrm{~kW}$. However, the flow rate used to produce this result is the product of the active turbine area and the velocity in the tank. If the given flow rate of $0.03 \mathrm{~m}^{3} / \mathrm{s}$ is applied to the same formula given, then the resulting power is $53 \mathrm{~W}$. This is not considered in the paper. Additionally, we used the traditional flow and head formula to calculate the power and found a theoretical maximum power of 294-353 W. The measured power output from the prototype was reported to be $150 \mathrm{~W}$.

\section{Summary}

Only six full papers concerned solely with GVHP have been found by the authors to date, with the earliest being from only 2013. Therefore, many questions concerning the operation of GVHP remain unanswered and there is a considerable knowledge gap. Experimental studies are particularly useful at this early stage in technology development. While four laboratory studies have been described to date, the results are not sufficiently detailed or generalizable. Also, the calculations used to generate the results are not provided. Therefore, the high efficiency and power claims, particularly in [29] need to be verified. Finally, there appears to have been little attempt to review and build on advances made in the area as none of the studies make reference to one another. For instance, a review of 'micro hydro gravitational vortex power and turbine systems' published in 2014 only mentions one of the studies reviewed here and gives little specific detail on GVHP [30].

There is also little detailed information from practice. The main commercial companies operating in the area are:

- Zotloeterer (www.zotloeterer.com)

- Kourispower (www.kourispower.com)

- GWWK (http://gwwk.ch/).

None of these companies have reached beyond prototype stage of their designs. The largest plant to date was developed in Switzerland by GWWK and has an annual energy output of between 80,000 and $130,000 \mathrm{kWh}$ (depending on flow rate).

\section{OBJECTIVES}

A literature review revealed that the optimal operating conditions of GVHP are largely unknown. In light of this knowledge gap, the objectives of this study are to explore the various operating conditions through a parametric experimental investigation and to find the optimal conditions for the laboratory scale model. The implications for practice of the results of this analysis are discussed in the final section.

\section{Methodology}

An experimental methodology was used for this study. The laboratory scale model was developed based on a literature review of previous experimental studies. A schematic diagram of the model is shown in Fig. 2.

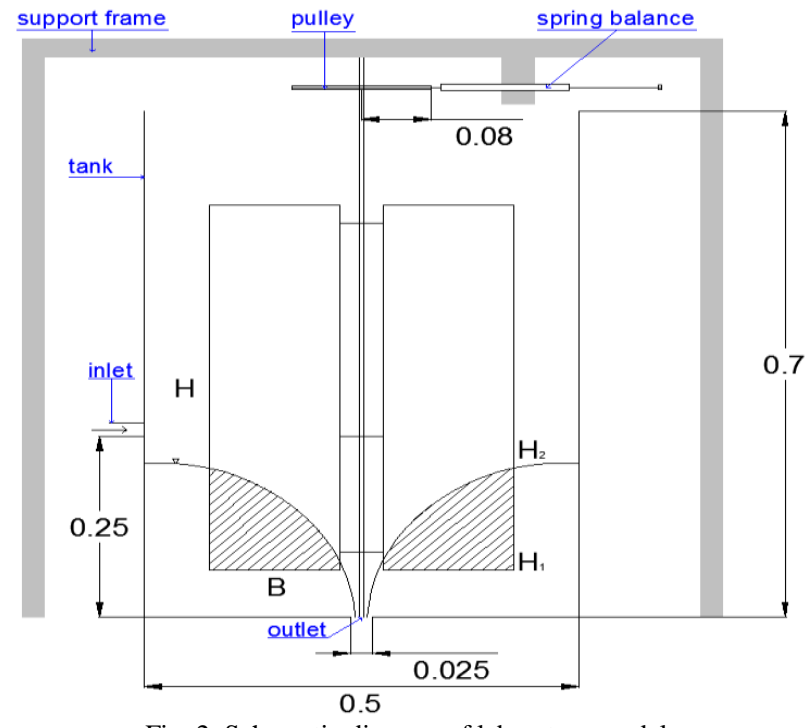

Fig. 2. Schematic diagram of laboratory model.

The model consists of a cylindrical tank with a tangential inlet pipe and a central outlet at the base. A vertical axis turbine with various rectangular blade sizes $(H \times B)$ and number configurations was located in the centre of the tank. The turbine braking force was measured using a dynamometer, which consisted of a pulley connected to the top of the turbine shaft and which was connected to two adjustable spring balances (SBs). The tension in the pulley and thus the SBs could be adjusted by tightening the screw on the bars connected to each of the SBs. The inflow rate was measured using an in-line flow meter connected to the inlet pipe. The turbine rotational speed was measured in RPM using a magnet attached to the top of the turbine shaft and a switch on the steel frame which opened and closed as the magnet passed by. RPM was recorded with a data logger as the number of times 
the switch opened per minute. While a constant water height was assumed by [28], the variation in vortex height with tank and turbine conditions was accounted for here by measuring the height for each new SB setting when testing the various turbine and inlet configurations. In line with [27], the vortex height was measured at its maximum, the outermost height at the tank wall.

The parameters under investigation in this study were selected based on a theoretical analysis of GVHP. The output power from a turbine is the product of torque, $T$, and angular speed, $\omega$, whereby the torque depends on the force of the water on the blades [31]. The force on each blade can be determined using (1), where $\rho$ is the water density $\left(\mathrm{kg} / \mathrm{m}^{3}\right), \omega$ is the turbine rotational speed ( $\mathrm{rad} / \mathrm{s}), B$ is the blade width (m) and $\left(H_{2}-H_{1}\right)$ is the height of the blade under water $(\mathrm{m})$.

$$
F_{\text {lblade }}=\int_{B_{1}}^{B_{2}} \frac{1}{2} \rho \omega^{2} B^{2}\left(H_{2}-H_{1}\right) d B=\frac{1}{2} \frac{\rho \omega^{2} B^{3}}{3}\left(H_{2}-H_{1}\right)
$$

According to (1), the force on the blades (and therefore the power output) can be increased by increasing $\omega, B$ and $\left(H_{2}-\right.$ $\left.H_{1}\right)$. However, while a larger blade will have an increased width, it will also be heavier thus having a negative impact on $\omega$. Similarly, while the total force can be increased by increasing the number of blades, the addition of each blade increases the overall weight of the turbine, thus slowing it down. Finally, $\omega$ and $\left(H_{2}-H_{1}\right)$ are also influenced by the rate of flow into the tank and by the height at which the flow hits the blades. Based on this theoretical understanding, the parameters chosen for investigation were:

1) Blade size,

2) Blade number,

3) Inlet flow rate $Q$,

4) Inlet height, IH, and

5) Turbine braking force $F$.

A parametric study was undertaken to investigate the effect of each of these parameters on the vortex height $H$, the turbine rotational speed $\omega$, the power produced by the turbine $P_{\text {OUT }}$, and the turbine efficiency $\eta$. Table I shows the various blade configurations chosen for the study. Each blade configuration is labelled; these labels will be used hereafter. For each blade configuration, tests were carried out for three inlet heights; 15 $\mathrm{cm}, 25 \mathrm{~cm}$ and $35 \mathrm{~cm}$ above the base of the tank. The only exception to this was turbine $V I$, which was tested only at two IHs because the inlet pipe obstructed the turbine rotation when placed $15 \mathrm{~cm}$ above the base. Two flow rates were tested at each inlet setting, a maximum of $0.65 \mathrm{~L} / \mathrm{s}$ when the inlet valve was fully open and a lower flow of $0.5-0.59 \mathrm{~L} / \mathrm{s}$.

The blade and inlet settings were constant for each test. The force resisting the turbine rotation was varied incrementally during each test by adjusting the SBs. Each force setting was allocated 3-4 minutes to allow the flow in the tank to stabilise following the change in turbine rotational speed. The resistance force was increased in steps from zero (turbine free-flow and maximum RPM) to the braking force required to stop the turbine. The procedure was repeated twice within each test to improve the reliability of the results, with the braking force being reached first by adjusting only the right SB and secondly by adjusting only the left SB. The water height in the tank (m), the turbine speed (RPM), and the SB readings $(\mathrm{N})$, were recorded for each force setting. The turbine RPM was periodically counted manually to verify the data logger readings. The testing sequence is shown in Table II, using the $500 \times 150 \times 2 \mathrm{~mm}$ blade turbine as an example.

TABLE I: TURBINE BLADE CONFIGURATIONS

\begin{tabular}{ccccc}
\hline \hline Label & Blade number & $H(\mathrm{~mm})$ & $B(\mathrm{~mm})$ & $W(\mathrm{~mm})$ \\
\hline$I$ & 2 & 500 & 150 & 2 \\
$I I$ & 4 & 500 & 150 & 2 \\
$I I I$ & 2 & 500 & 150 & 1.5 \\
$I V$ & 2 & 500 & 75 & 1.5 \\
$V$ & 4 & 500 & 75 & 1.5 \\
$V I$ & 2 & 500 & 200 & 1.5 \\
$V I I$ & 2 & 250 & 150 & 1.5 \\
$V I I I$ & 4 & 250 & 150 & 1.5 \\
$I X$ & 2 & 250 & 100 & 1.5 \\
\hline \hline
\end{tabular}

TABLE II: SAMPLE TESTING SEQUENCE $(500 \times 150 \times 2$ MM BLADE TURBINE)

\begin{tabular}{cccc}
\hline \hline $\begin{array}{c}\text { Blade } \\
\text { number }\end{array}$ & $Q(\mathrm{~L} / \mathrm{s})$ & $\mathrm{IH}(\mathrm{cm})$ & Measurements taken \\
\hline 2 & 0.65 & 15 & 15-18 SB settings. 3-4 min per \\
& & 25 & setting. Record time, SB forces, water \\
& & 35 & height and RPM per setting. \\
\hline 2 & 0.54 & 15 & 10-15 SB settings. 3-4 min per \\
& & 35 & setting. Record time, SB forces, water \\
& & height and RPM per setting. \\
\hline \hline
\end{tabular}

The input and output powers and the turbine efficiency were calculated for all of the tests using equations (2)-(5).

$$
\begin{gathered}
P_{I N}=\rho g H Q \\
T=F r \\
P_{O U T}=T \omega \\
\eta=\frac{P_{O U T}}{P_{I N}} .100
\end{gathered}
$$

\section{RESULTS AND DISCUSSION}

\section{A. Blade Size}

As listed in Table I, six blade sizes were tested, ranging from blade areas of $0.025 \mathrm{~mm}^{2}$ to $0.1 \mathrm{~mm}^{2}$. Because a larger blade is heavier than a smaller one, the turbine weight increases with increasing blade area, resulting in reduced vortex heights and turbine speeds. In accordance with (2), the power input was found to decrease as the vortex height $H$ in the tank dropped with increasing blade area. The decrease in $\omega$ with increased blade size impacts negatively on the power produced by the turbine, as dictated by (4). However, the resistance force (and therefore torque) needed to stop the larger (and heavier) blades was found to be much greater than for the smaller blades. This had the effect of increasing the turbine power output with blade size. As can be seen in Fig. 3, the efficiency was also found to mostly increase with blade size. The largest recorded efficiency, $15.1 \%$, was found with 
two of the largest blade turbines, $I I I$ and $V I$. In both cases, this occurred at the largest inflow rate $(0.65 \mathrm{~L} / \mathrm{s})$ and at an $\mathrm{IH}$ of 25 $\mathrm{cm}$.

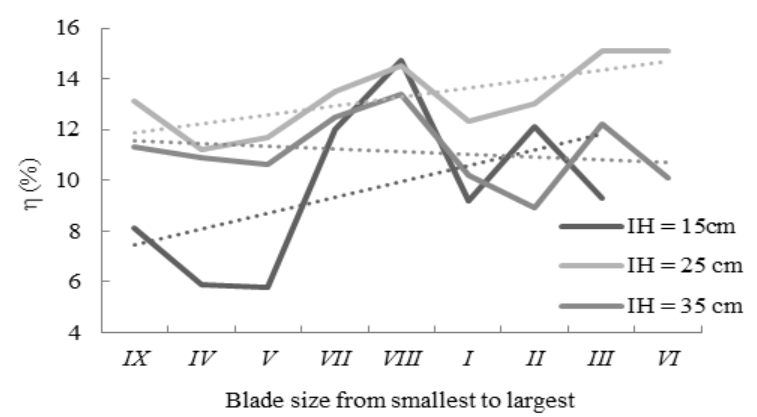

Fig. 3. Variation in turbine efficiency with increasing blade size $(Q=0.65$ $\mathrm{L} / \mathrm{s})$.

\section{B. Blade Number}

The increase in blade number had a similar overall effect as the increase in blade area, since both increases led to heavier turbines. The increased turbine weight due to the addition of blades resulted in slower turbine rotation and a reduced vortex height. The impact of blade number on braking force is less clear, however, as $F$ was found to both increase and decrease with the addition of blades, depending on the blade size. This variation in braking force with blade number is shown in Table III, for all three IHs tested at the maximum flow rate of $0.65 \mathrm{~L} / \mathrm{s}$. An increase in braking force caused by the increase of the blade number from two to four is denoted by $(\uparrow)$, a decrease by $(\downarrow)$ and no change by (-).

TABLE III: VARIATION IN TURBINE BRAKING FORCE WITH INCREASING BLADE NUMBER $(Q=0.65 \mathrm{~L} / \mathrm{s})$

\begin{tabular}{cccc}
\hline \hline Blade configuration & $\mathrm{IH}=15 \mathrm{~cm}$ & $\mathrm{IH}=25 \mathrm{~cm}$ & $\mathrm{IH}=35 \mathrm{~cm}$ \\
$(2 \rightarrow 4$ blades $)$ & $F(\mathrm{~N})$ & $F(\mathrm{~N})$ & $F(\mathrm{~N})$ \\
\hline$I \rightarrow I I$ & $\downarrow$ & $\downarrow$ & $\downarrow$ \\
$I V \rightarrow V$ & $\uparrow$ & - & $\uparrow$ \\
$V I I \rightarrow V I I I$ & $\uparrow$ & $\downarrow$ & $\uparrow$ \\
\hline \hline
\end{tabular}

A stronger relationship was found between blade number and turbine performance, with both power output and efficiency, mostly increasing as the blade number increased from two to four. The variation in turbine efficiency with increasing blade number is shown in Table IV. The turbine was more efficient with four blades rather than two in two-thirds of the cases examined. At a $35 \mathrm{~cm} \mathrm{IH}$, the efficiency decreased for two of the three blade sizes tested.

TABLE IV: VARIATION IN TURBINE EFFICIENCY WITH INCREASING BLADE NUMBER $(Q=0.65 \mathrm{~L} / \mathrm{s})$

\begin{tabular}{cccc}
\hline \hline Blade configuration & $\mathrm{IH}=15 \mathrm{~cm}$ & $\mathrm{IH}=25 \mathrm{~cm}$ & $\mathrm{IH}=35 \mathrm{~cm}$ \\
$(2 \rightarrow 4$ blades $)$ & $F(\mathrm{~N})$ & $F(\mathrm{~N})$ & $F(\mathrm{~N})$ \\
\hline$I \rightarrow I I$ & $\uparrow$ & $\uparrow$ & $\downarrow$ \\
$I V \rightarrow V$ & $\downarrow$ & $\uparrow$ & $\downarrow$ \\
$V I I \rightarrow V I I I$ & $\uparrow$ & $\uparrow$ & $\uparrow$ \\
\hline \hline
\end{tabular}

\section{Inlet Flow Rate}

As to be expected, the greatest vortex heights, turbine speeds, braking forces and power outputs were found for all blade configurations and IHs at the maximum inflow rate of
$0.65 \mathrm{~L} / \mathrm{s}$. This is in accordance with (2) which show that a reduction in the inflow rate causes a decrease in the potential power available. As can be seen in Fig. 4, the turbine performance at partial flows varies with blade configuration. Because different partial flow rates were tested for each blade configuration, the ratios of partial flows to maximum flows are shown on a line graph in Fig. 4.

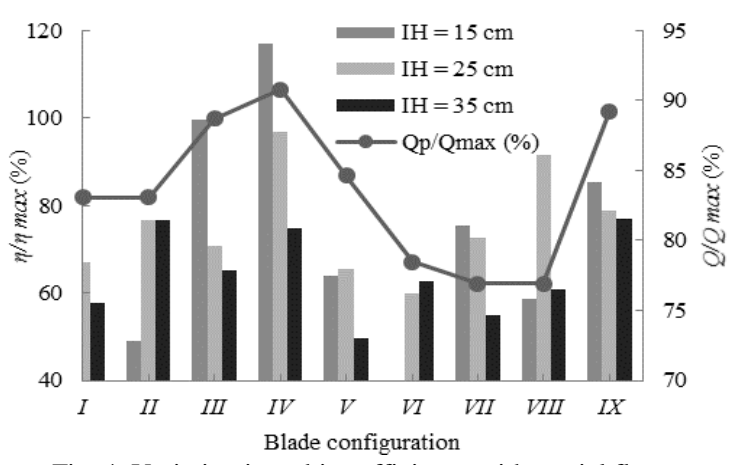

Fig. 4. Variation in turbine efficiency with partial flows.

It is difficult to ascertain a trend as the turbines each perform differently depending on the IH. On comparing the partial efficiencies at the three IHs, the $15 \mathrm{~cm}$ IH resulted in the smallest drops in efficiency with flow rate for five of the 8 turbines. Also the largest partial efficiency ratio was recorded at an $\mathrm{IH}$ of $15 \mathrm{~cm}$. Overall, the greatest drops in efficiency with flow rate were found when the inlet was placed $35 \mathrm{~cm}$ above the base of the tank. Fig. 4 shows that turbine $I V$ outperformed the other 7 turbines, as it resulted in the largest partial efficiencies for the $15 \mathrm{~cm}$ and $25 \mathrm{~cm}$ IHs. Turbine $I X$ produced the largest partial efficiency at the $35 \mathrm{~cm} \mathrm{IH}$, followed closely by $I I$ and $I V$.

The performance of turbine $I V$ at the $15 \mathrm{~cm} \mathrm{IH}$ is an anomaly since the efficiency was found to be greater when the inflow rate was reduced. While a considerably larger resistance force was required to stop the turbine when the valve was fully open $(0.55 \mathrm{~N}$ versus $0.36 \mathrm{~N}$ at the lower flow rate), the rotational speed was found to drop only slightly when the flow rate was reduced. The larger inflow rate produced a maximum turbine rotational speed of 50 RPM, while the reduced inflow produced 49.5 RPM. Therefore, the maximum power output dropped only marginally from 0.07 $\mathrm{W}$ to $0.067 \mathrm{~W}$ when the inflow rate was reduced. However, the larger inflow rate produced a much higher vortex height and therefore power input, resulting in a reduced turbine efficiency at the larger flow rate. The efficiency increased from $5.9 \%$ at $0.65 \mathrm{~L} / \mathrm{s}$ to $6.9 \%$ at $0.59 \mathrm{~L} / \mathrm{s}$.

\section{Inlet Height}

A considerable variation in turbine performance was found when the inlet pipe was placed at different heights within the tank. The optimal IH was found to be $25 \mathrm{~cm}$ for all blade configurations, as this inlet setting resulted in the greatest water heights, turbine speeds and efficiencies. As can be seen in Fig. 5, the maximum efficiency was found at an IH of $25 \mathrm{~cm}$ for all flow rates in all cases except one, $I V$, which performs best at an IH of $15 \mathrm{~cm}$. However, the difference in efficiency between the two IHs is minimal; $14.7 \%$ at an IH of $15 \mathrm{~cm}$ and $14.5 \%$ at an $\mathrm{IH}$ of $25 \mathrm{~cm}$. The overall tank height is $0.7 \mathrm{~m}$, so the optimal IH is just over one-third of the way up the tank. 


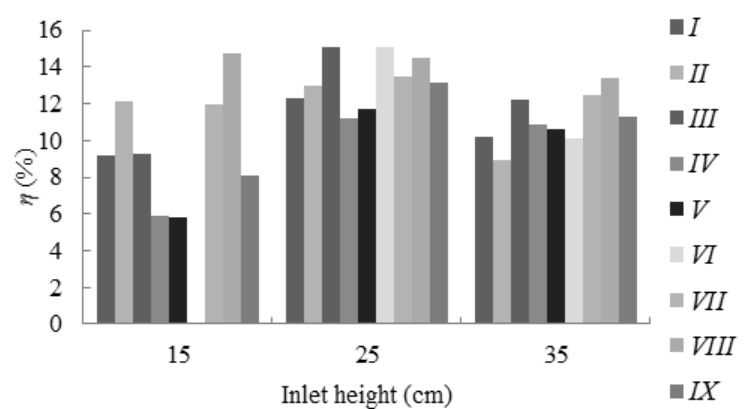

Fig. 5. Variation in turbine efficiency with inlet height $(Q=0.65 \mathrm{~L} / \mathrm{s})$.

It is difficult to rank the $15 \mathrm{~cm}$ and $35 \mathrm{~cm}$ IHs as they each performed well for different parameters. After the $25 \mathrm{~cm} \mathrm{IH}$, the $15 \mathrm{~cm} \mathrm{IH}$ resulted mostly in the greatest water heights, whereas the turbines were mostly faster when the inlet was placed $35 \mathrm{~cm}$ from the base of the tank. For 6 of the 9 blade configurations, the worst efficiencies were recorded when the IH was $15 \mathrm{~cm}$.

\section{E. Turbine Resistance Force}

As the SB was adjusted to increase the resistance to the turbine movement, $\omega$ naturally dropped leading to a reduced water height in the tank. However, because the power output depends not only on $\omega$ but also on the torque due to the resistance force, the maximum power outputs and efficiencies were found when a relatively large force was applied. For all of the blade configurations, the optimum SB setting appears to lie around half way between a zero force reading (turbine free flow) and the maximum force reading which corresponds to no turbine rotation. At both of these limiting points there is no power output.

The effect of increasing the resistance force on both the available power and the power produced by the turbine is shown in Table $\mathrm{V}$, using turbine $I$ as an example. The results shown are for a $0.65 \mathrm{~L} / \mathrm{s}$ inflow rate and a $25 \mathrm{~cm} \mathrm{IH}$, as the highest efficiencies were recorded at these settings. The maximum values of each of the parameters are highlighted in bold. As to be expected from (2), the maximum input power was found at the minimum applied force since this resulted in the greatest water height (head). The output power however increased with increased resistance force. The highest efficiency corresponded to the largest output power, at a force just under half of the maximum applied force.

TABLE V: VARIATION IN TURBINE PERFORMANCE WITH INCREASING RESISTANCE FORCE FOR TURBINE $I(Q=0.65 \mathrm{~L} / \mathrm{s}, \mathrm{IH}=25 \mathrm{CM})$

\begin{tabular}{cccccc}
\hline \hline$F(\mathrm{~N})$ & $H(\mathrm{~m})$ & $\omega(\mathrm{rad} / \mathrm{s})$ & $P_{\text {out }}(\mathrm{W})$ & $P_{\text {in }}(\mathrm{W})$ & $\eta(\%)$ \\
\hline 0.2375 & $\mathbf{0 . 1 8 7 5}$ & $\mathbf{5 . 1 3 1}$ & 0.099 & $\mathbf{1 . 1 9 5}$ & 8.28 \\
0.2875 & 0.1775 & 4.817 & 0.112 & 1.131 & 9.94 \\
0.2875 & 0.1775 & 4.712 & 0.11 & 1.131 & 9.72 \\
0.4375 & 0.1825 & 4.032 & $\mathbf{0 . 1 4 3}$ & 1.163 & $\mathbf{1 2 . 3 1}$ \\
0.5 & 0.1725 & 3.246 & 0.132 & 1.100 & 11.99 \\
0.525 & 0.1775 & 2.932 & 0.125 & 1.131 & 11.05 \\
0.7 & 0.1675 & 1.414 & 0.08 & 1.068 & 7.53 \\
0.7125 & 0.1675 & 1.571 & 0.091 & 1.068 & 8.51 \\
0.7125 & 0.1625 & 1.257 & 0.073 & 1.036 & 7.02 \\
0.725 & 0.1675 & 1.466 & 0.0863 & 1.068 & 8.08 \\
$\mathbf{0 . 7 5}$ & 0.1675 & 1.466 & 0.089 & 1.068 & 8.36 \\
\hline \hline
\end{tabular}

\section{F. Summary}

A parametric experimental study was carried out to investigate the operating conditions of GVHP. The turbine parameters varied were blade size and blade number, with both being found to have a similar effect on turbine performance. Increasing the blade size and/or number had the effect of increasing the turbine weight, resulting in lower vortex heights and turbine speeds but higher turbine power outputs and efficiencies. It can be said, therefore, that further optimization studies should focus on larger blades and increased blade numbers using lighter blade materials.

For all of the blade configurations tested, the maximum vortex heights, turbine speeds, powers and efficiencies were found when the inlet valve was fully open (producing a flow rate of $0.65 \mathrm{~L} / \mathrm{s}$ ) compared with lower flow rates of $0.5-0.59$ $\mathrm{L} / \mathrm{s}$. The maximum vortex height recorded when the valve was fully open was $0.213 \mathrm{~m}$ (with turbine $I V$ ). This is less than one-third of the tank height. Therefore, a larger flow rate or a smaller outlet diameter should be tested to increase the vortex height and thus power input. With regards to the location of the inlet pipe, the optimal height was found to be $25 \mathrm{~cm}$, as this resulted in the maximum turbine efficiencies for all turbines except one.

Finally, a resistance force was applied using a SB dynamometer during the testing of the turbines. Both the vortex height and the turbine speed were found to decrease as the applied force was increased. The power output and efficiency of the turbine were found to increase to a maximum point with increased force, then decrease thereafter with additional force. The maximum efficiency occurred at different SB settings depending on the blade configuration and inlet settings. However, the optimal force was always around half way between zero applied force and the maximum force required to stop the turbine completely. The overall maximum efficiency recorded was with the largest blade area, the maximum inflow rate, the $25 \mathrm{~cm} \mathrm{IH}$, and a resistance force equal to $60 \%$ of the maximum force applied.

\section{IMPLICATIONS FOR PRACTICE}

\section{A. Run-of-River}

GVHP is a potential hydropower solution for low head rivers because the power output depends on the vortex height, as determined by the water flow rate and the tank size, rather than the change in river elevation. In the past, SHP schemes have often proven to be expensive and uneconomical due to the use of conventional turbines designed for large hydroelectric plants [8], [32]. Typically, turbine and electro-mechanical costs account for around $30-40 \%$ of the overall investment for an SHP scheme [33]. In comparing GVHP with traditional run-of-river schemes, the turbine arrangement is much simpler for GVHP and so turbine costs will be lower. However, the overall civil construction costs can still be expected to be high for GVHP as the river needs to be directed (either partially or fully) into a man-made concrete circular tank to generate the vortex.

Dimensional analysis should be used to scale the results of the laboratory model presented here for a river setting. Based on the results of this paper, future research will focus on a smaller outlet diameter to generate higher water vortices, and larger blade sizes and numbers. A cost-benefit analysis should be included because costs (as well as power and efficiency) 
increase as the turbine size increases.

\section{B. Water and Wastewater Networks}

Given the considerable flows within water and wastewater networks, hydropower presents an opportunity to reduce the environmental and economic costs of the water industry. Environmental benefits of using these networks for hydropower generation include the absence of traditional barriers, such as visual intrusion, impact on aquatic ecosystems, loss of historical sites, interruption of sediment transport and blockage of fish passage. Also, there are often economic advantages over traditional SHP schemes due to reduced earthworks and infrastructure requirements [34]-[36] Because potable water is typically distributed by gravity from an upper central reservoir to consumers at lower elevations, high heads can be found within the water network. Hydropower turbines are being installed at these locations of high head and flow in the water network, such as at pressure reducing valves and municipal supply dams [37], [38].

The wastewater network in comparison is typically characterised as being low head. Hydropower opportunities have been identified at the inlets and outlets of wastewater treatment plants, particularly in large urban and industrial plants where the presence of high flows makes up for the small drops in elevation. The exploitation of these opportunities in practice relies on the development of low head hydropower solutions that are suitable for wastewater flows. Hydropower generation is particularly challenging in the untreated wastewater network, as the high solids content of raw sewage can create problems for traditional turbines, such as increased wear and tear and clogging of the rotating parts [39], [40]. In addition to operating at ultra-low heads, GVHP is especially suited to the wastewater network because any solids are naturally separated by the vortex flow. As illustrated in the operation of cyclonic separators, the centrifugal action of a vortex forces the heavier fluid (containing the solids) to separate from the lighter fluid [41]. Finally, GVHP has real potential for wastewater networks because vortices are often found to occur naturally within the infrastructure, such as at pumping stations.

\section{CONCLUSION AND RECOMMENDATIONS}

The maximum efficiency was found to be $15.1 \%$. This was found with the largest blade area, the maximum inflow rate, the $25 \mathrm{~cm} \mathrm{IH}$, and a resistance force equal to $60 \%$ of the maximum force applied. Much higher efficiencies of up to $80 \%$ have been reported by commercial companies and up to $30 \%$ by experimental research studies. However, these results largely lack validation. Future research will focus on further testing the outcomes of this paper, by experimenting with larger blades, increased blade numbers and smaller outlet diameters to further optimize GVHP operation.

\section{ACKNOWLEDGMENT}

The authors thank the civil engineering technical staff at Trinity College for their continuing help in developing and updating the GVHP laboratory model. This research was part funded by the European Regional Development Fund through the INTERREG Ireland-Wales Programme (Interreg 4A).

\section{REFERENCES}

[1] International Energy Agency, Key World Energy Statistics, Paris, France, 2014.

[2] Y. Krozer, "Cost and benefit of renewable energy in the European Union," Renewable Energy, vol. 50, pp. 68-73, 2013.

[3] N. Alrikabi, "Renewable energy types," Journal of Clean Energy Technologies, vol. 2, no. 1, pp. 61-64, 2014

[4] J. Brown, Water Power and Watermills-An Historical Guide, $1^{\text {st }}$ ed Wiltshire, U.K.: Crowood Press, 2011.

[5] IPCC, Special Report on Renewable Energy Sources and Climate Change Mitigation, Cambridge University Press, 2011.

[6] European Small Hydropower Association, State of the Art of Small Hydropower in EU-25, Brussels, Belgium, 2006.

[7] B. Hamududu and A. Killingtveit, "Assessing climate change impacts on global hydropower," Energies, vol. 5, 2012.

[8] J. A. Laghari, H. Mokhlis, A. H. A. Bakar, and H. Mohammad, "A comprehensive overview of new designs in the hydraulic, electrical equipments and controllers of mini hydro power plants making it cost effective technology," Renewable \& Sustainable Energy Reviews, vol 20, pp. 279-293, 2013.

[9] O. Paish, "Small hydro power: Technology and current status," Renewable \& Sustainable Energy Reviews, vol. 6, no. 6, pp. 537-556, 2002.

[10] T. Abbasi and S. A. Abbasi, "Small hydro and the environmental implications of its extensive utilization," Renewable and Sustainable Energy Reviews, vol. 15, no. 4, pp. 2134-2143, 2011.

[11] European Small Hydropower Association, Guide on How to Develop a Small Hydropower Plant, Brussels, Belgium, 2004.

[12] R. J. Campbell, Small Hydro and Low-Head Hydro Power Technologies and Prospects, Congressional Research Service, Washington D.C., USA, 2010.

[13] S. Bozhinova, V. Hecht, D. Kisliakov, G. Muller, and S. Schneider, "Hydropower converters with head differences below 2.5m," Proceedings of the Institution of Civil Engineers, 2012.

[14] Schematic diagram of GVHP. [Online]. Available: http://en.wikipedia.org/wiki/Gravitation_water_vortex_power_plant\# mediaviewer/File:Wasserwirbelkraftwerk.jpg

[15] P. Basu, D. Agarwal, T. J. Tharakan, and A. Salih, "Numerical studies on air-core vortex formation during draining of liquids from tanks," International Journal of Fluid Mechanics Research, vol. 40, no. 1, pp. $27-41,2013$

[16] L. L. Daggett and G. H. Keulegan, "Similitude conditions in free-surface vortex formations," Journal of the Hydraulics Division, vol. 100, no. 11, pp. 1565-1581, 1974.

[17] A. Odgaard, "Free surface air core vortex," Journal of Hydraulic Engineering, vol. 112, no. 7, pp. 610-620, 1986.

[18] H. Safikhani, A. Hajiloo, and M. A. Ranjbar, "Modeling and multi-objective optimization of cyclone separators using CFD and genetic algorithms," Computers \& Chemical Engineering, vol. 35, no. 6, pp. 1064-1071, 2011.

[19] R. Utikar et al., "Hydrodynamic simulation of cyclone separators," in Computational Fluid Dynamics, H. W. Oh, Ed. InTech., 2010, ch. 11

[20] J. Hite and W. Mih, "Velocity of air - Core vortices at hydraulic intakes," Journal of Hydraulic Engineering, vol. 120, no. 3, pp. 284-297, 1994.

[21] V. Rajendran, S. Constantinescu, and V. Patel, "Experimental validation of numerical model of flow in pump-intake bays," Journal of Hydraulic Engineering, vol. 125, no. 11, pp. 1119-1125, 1999.

[22] P. Wiemann, G. Müller, and J. Senior, "Review of current developments in low head, small hydropower," presented at the 32nd IAHR Conference 2007, Venice, Italy, 2007.

[23] Applegate Group Inc. and Colorado State University, Exploring the Viability of Low Head Hydro in Colorado's Existing Irrigation Infrastructure, Interim Report, Summary of Available Low Head Turbine Technologies, Colorado, USA, 2010.

[24] M. Gheorghe-Marius et al., "The concept and theoretical study of micro hydropower plant with gravitational vortex and turbine with rapidity steps," Buletinul AGIR, vol. 3, 2012.

[25] S. Wanchat and R. Suntivarakorn, "Preliminary design of a vortex pool for electrical generation," Advanced Science Letters, vol. 13, no. 1, pp. 173-177, 2012.

[26] S. Wanchat, R. Suntivarakorn, S. Wanchat, K. Tonmit, and P. Kayanyiem, "A parametric study of a gravitation vortex power plant," Advanced Materials Research, vol. 805-806, pp. 811-817, 2013. 
[27] T. C. Kueh, S. L. Beh, D. Rilling, and Y. Ooi, "Numerical analysis of water vortex formation for the water vortex power plant," International Journal of Innovation, Management and Technology, vol. 5, no. 2, pp. 111-115, 2014.

[28] S. Dhakal, S. Nakarmi, P. Pun, A. B. Thapa, and T. R. Bajracharya, "Development and testing of runner and conical basin for gravitational water vortex power plant," Journal of the Institute of Engineering, vol. 10 , no. 1 , pp. $140-148,2014$

[29] A. Venukumar, "Artificial vortex (ArVo) power generation - An innovative micro hydroelectric power," in Proc. Global Humanitarian Technology Conference: South Asia Satellite (GHTC-SAS), 2013.

[30] O. B. Yaakoba, Y. M. Ahmeda, A. H. Elbatrana, and H. M. Shabaraa, "A review on micro hydro gravitational vortex power and turbine systems," Journal Technology, vol. 69, no. 7, pp. 1-7, 2014.

[31] R. Gopinath, "Design of a rope brake dynamometer," Middle-East Journal of Scientific Research, vol. 20, no. 5, pp. 650-655, 2014.

[32] K. V. Alexander, E. P. Giddens, and A. M. Fuller, "Axial-flow turbines for low head micro-hydro systems," Renewable Energy, vol. 34, no. 1 , pp. 35-47, 2009

[33] D. K. Okot, "Review of small hydropower technology," Renewable and Sustainable Energy Reviews, vol. 26, pp. 515-520, 2013

[34] P. D. Zakkour, M. R. Gaterell, P. Griffin, R. J. Gochin, and L. J. N. Lester, "Developing a sustainable energy strategy for a water utility. Part II: A review of potential technologies and approaches," Journal of Environmental Management, vol. 66, no. 2, pp. 115-125, 2002.

[35] K. J. Chae and J. Kang, "Estimating the energy independence of a municipal wastewater treatment plant incorporating green energy resources," Energy Conversion and Management, vol. 75, pp. 664-672, 2013.

[36] T. Gaius-Obaseki, "Hydropower opportunities in the water industry," International Journal of Environmental Sciences, vol. 1, no. 3, 2010

[37] A. McNabola et al., "Energy recovery in the water industry using micro-hydropower: an opportunity to improve sustainability," Water Policy, vol. 16, no. 1, pp. 168-183, 2014.

[38] H. M. Ramos, M. Mello, and P. K. De, "Clean power in water supply systems as a sustainable solution: from planning to practical implementation," Water Science \& Technology: Water Supply, vol. 10, no. 1, pp. 39-49, 2010.

[39] C. Power, A. McNabola, and P. Coughlan, "Development of an evaluation method for hydropower energy recovery in wastewater treatment plants: Case studies in Ireland and the UK," Sustainable Energy Technologies and Assessments, vol. 7, pp. 166-177, 2014.

[40] A. Choulot, V. Denis, and P. Punys, "Integration of small hydro turbines into existing water infrastructures," in Hydropower-Practice and Application, H. Samadi-Boroujeni, Ed. InTech., 2012, ch. 12.

[41] A. Gupta and R. Kumar, "Three-dimensional turbulent swirling flow in a cylinder: Experiments and computations," International Journal of Heat and Fluid Flow, vol. 28, no. 2, pp. 249-261, 2007.

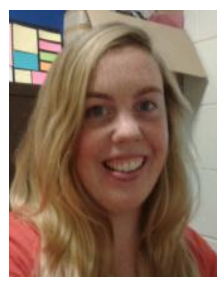

Christine Power is currently undertaking the Ph.D. degree between the schools of engineering and business in Trinity College Dublin (expected completion date is September 2015). She graduated from University College Cork with a First Class Honours bachelor's degree in civil and environmental engineering in 2010. She also earned a postgraduate diploma in sustainable energy from Trinity College Dublin in 2013 and a postgraduate certificate in innovation and entrepreneurship from the Innovation Academy, Dublin in 2014.

The focus of Christine's doctoral research is energy recovery from wastewater infrastructure using micro hydropower turbines. The technical and economic feasibility of hydropower energy recovery at wastewater treatment plant outfalls was assessed for over 100 plants and an evaluation method to aid future feasibility assessments was developed, the results of which were published in Sustainable Energy Technologies and Assessments in 2014. This evaluation revealed that while outfall-hydropower is an economically viable energy recovery option for large treatment plants, head is a technical constraint, with many of the viable outfalls having drops of less than $5 \mathrm{~m}$. This research insight led to the investigation of GVHP. Her laboratory experimentation in conjunction with numerical modelling are being used to explore and optimise the operating conditions of GVHP. The final element of her Ph.D. research is around understanding how best to implement a hydropower energy recovery project in practice. Her case study research is being used to explore how previous such projects were implemented and to develop guidelines to ensure the success of future energy recovery projects.

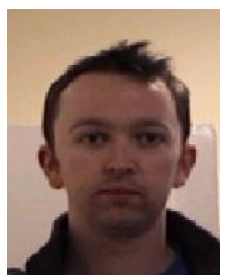

Aonghus McNabola is a graduate of the School of Engineering, Trinity College Dublin, he obtained his primary degree in 2002 . He subsequently worked in Engineering Consultancy for 2 years as a civil \& environmental engineer. Then he carried out a $\mathrm{PhD}$ degree at Trinity College Dublin, graduated in 2007 The subject of his research was in air pollution measurement and CFD modelling of commuter traffic in Dublin. He worked as a postdoctoral research fellow at TCD on biofuel production prior to being appointed as an assistant professor in energy and environment in the Dept. of Civil, Structural and Environmental Engineering, TCD. Since his appointment Dr. McNabola has continued his research work in the fields of air pollution and CFD analysis, focusing on many aspects such as: air pollution control device development, health impacts, emissions modelling, exposure assessment and modelling. He has also expanded his work into the area of energy efficiency including projects in energy recovery in the water industry and energy recovery in buildings. His research interests include the application of CFD analysis to engineering problems such as air pollution dispersion, fluid structure interactions, energy devices (hydro/energy recovery); the study of air pollution exposure and its impact on human health; and the recovery of energy in urban systems.

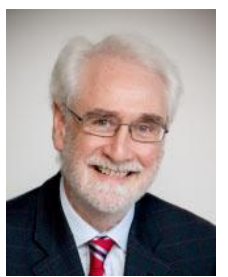

Paul Coughlan is a professor of operations management and the director of research at the Schoo of Business, Trinity College Dublin. Followed by an early career in engineering management he became a university lecturer and then a full-time doctoral student at the Business School of the University of Western Ontario (now the Ivey School). After graduation, he joined the Faculty of the London Business School. Then he joined Trinity's School of Business and has developed his research and teaching in operations management and new product development. At Trinity, in addition to his research and teaching works, he also held many senior school and college administrative positions, including the MBA director, director of postgraduate teaching \& learning and course co-director at the TCD-UCD Innovation Academy. Outside of Trinity College, he was the president of the European Institute for Advanced Studies in Management (EIASM) from 2003-2009. His research in product development and continuous improvement has encompassed an innovative action research dimension involving companies engaged in action learning. This work has led to continuing methodology development and to specialised doctoral training in action research and learning through the EIASM doctoral network. 